\title{
FIXERS: CONTRACULTURA EM ASCENSÃO
}

\author{
FIXERS: CONTRACCULTURE IN ASCENSION
}

\author{
DANIELA NEUMANN | UFRGS \\ RODOLFO ROLIM DALLA COSTA, M.SC. | UFRGS \\ JOCELISE JACQUES DE JACQUES, DRA. | UFRGS \\ JULIO CARLOS DE SOUZA VAN DER LINDEN, DR. | UFRGS
}

\begin{abstract}
RESUMO
Esta pesquisa consiste no estudo de grupos conhecidos como fixers. Apresentando como principal objetivo, descobrir, analisar e compreender a organização, missão, motivação e valores destes grupos, considerados atualmente como uma contracultura em franco desenvolvimento. Estes consertadores estimulam a prática de consertar produtos, promovendo encontros nos quais as pessoas levam seus objetos avariados para consertá-los gratuitamente, prolongando a sua vida útil e aprendendo a repará-los no caso de uma nova necessidade. Também são abordados temas como o consumo, a obsolescência e a sustentabilidade sob a perspectiva do design, para melhor compreender o aparecimento destes grupos. Esta pesquisa segue uma abordagem de caráter exploratório qualitativo, de natureza interpretativa e descritiva, sendo a coleta de dados feita por meio de um questionário aberto, obtendo a resposta de um grupo brasileiro e quatorze grupos estrangeiros de conserto. O estudo traz contribuições para o debate sobre a necessidade de reduzir a acelerada demanda de produção, consumo e obsolescência dos produtos. e a ocorrência de diversos impactos ambientais resultantes destes fatores. Colaborando com implicações teóricas para o campo do design, para o alcance de uma sociedade mais sustentável e o desenvolvimento de futuros projetos relacionado aos grupos fixers.
\end{abstract}

PALAVRAS CHAVE: Design; Consumo; Contracultura; Fixers; Obsolescência

\begin{abstract}
This research studies the groups known as fixers and the main purpose of this paper is to disclose, to analyze and to understand the organization, mission, motivation and values of these groups, considered a developing counterculture. These groups stimulate the practice of fixing products, promoting meetings in which people take their objectives to repair for free, extending its lifespan and learning to improve them in case of a new necessity. Additionally, other questions are going to be approached as consume, obsolescence and sustainability under design's perspective to discern why these groups surged. This research follows a qualitative exploratory study, with an interpretative and descriptive nature, based on a data collection obtained through an open questionnaire, resulting in answers of one Brazilian fixing group and fourteen foreign fixing groups. This way, many contributions to reduce the increasing production demand, consume and obsolescence of the products appeared and the occurrence of many environmental impacts resulting of these factors. Also collaborating with theory consequences to design area, achieving a more sustainable society and the development of future projects related to fixers.
\end{abstract}

KEYWORDS: Desig; Consumerism; Contraculture; Fixer; Obsolescence 


\section{INTRODUÇÃO}

Considerada pelo filósofo francês Lipovetsky (2009) como efêmera e pelo sociólogo polonês Bauman (2015) como líquida, a sociedade é definida por rápidas e frequentes transformações culturais, econômicas e sociais. Os diversos avanços tecnológicos também incentivam esta nova organização da sociedade, centrada no aparecimento incessante de novos desejos e necessidades na qual a produção e o consumo são regidos sob "a lei da obsolescência, da sedução e da diversificação" (LIPOVETSKY, 2009, p. 208), a qual dita que o novo será sempre superior ao antigo, estimulando o desuso e o descarte prematuro dos produtos consumidos.

A acelerada procura por novos produtos é um problema a ser enfrentado, tanto pelo poder público, quanto pela sociedade. Comprar para o indivíduo contemporâneo transformou-se em um ato de criação, de identidade, de identificação, expressão e comunicação (FEATHERSTONE, 1997). Soma-se a isso o constante incentivo do governo para que as empresas expandam sua produção e aumentem sua competitividade, proporcionando um estímulo cada vez maior ao consumo "[...] o que revela um pouco da psicologia de desperdício que domina a cultura industrial contemporânea" (CARDOSO, 2008, p. 249).

Emerge nesse cenário a obsolescência acelerada dos produtos tornando-os rapidamente ultrapassados e forçando os usuários a descartarem o recente produto comprado e obterem um produto novo, que possivelmente atenderá a uma nova necessidade inventada (MAGERA, 2003). Em um curto espaço de tempo, a obsolescência aumentou um dos mais graves impactos ambientais a serem enfrentados pela humanidade: a gestão dos resíduos provenientes do processo de consumo desenfreado (MARLET, 2005).

Surge, por intermédio disto, a busca por alternativas viáveis para o descarte de resíduos. Segundo Thackara (2008), a sustentabilidade baseia-se no planejamento de ações, para que seja retomada a ação humana ao invés de substituí-la regularmente pela tecnologia, baseando o mundo mais em pessoas e menos em coisas. A sustentabilidade busca um processo de reposicionamento nos modos de vida da sociedade e isso, necessita de um processo de aprendizado coletivo que é por natureza, demorado e complexo (SANTOS, 2009). Por isso, ações que intentam repensar a gestão da obsolescência e a redução do consumo, devem ser privilegiadas e colocadas em prática.

$O$ design enquanto atividade envolvida diretamente no planejamento e no desenvolvimento de boa parte da cultura material tem colaborado diretamente para acelerar o processo de obsolescência dos produtos. Para Sudjic
(2010), o design é utilizado não somente para suprir necessidades, mas também para manter a sociedade regulada sobre parâmetros da aparência, moda e ostentação, no qual a instantânea satisfação da aquisição pode ser destacada como a causa e a consequência da elevada obsolescência dos desejos.

Por outro lado "o design é um elemento essencial de todas as atividades humanas - [...] e a elaboração de qualquer ação visando uma meta desejada, constituído um processo de planejamento" (PAPANEK, 1972, p. 23), podendo ser estimado como uma poderosa ferramenta no processo de inovação social e sustentabilidade, participando da redução do consumo e da obsolescência e incentivando a transição para padrões de produção e consumo ambientalmente amigáveis.

Esta pesquisa procura analisar as estratégias de grupos conhecidos como fixers (termo em inglês que pode ser traduzido como "consertadores", em português) que promovem o conserto de produtos. A principal estratégia destes grupos é reduzir o consumo e a rápida obsolescência dos produtos por meio de encontros nos quais os usuários possam levar seus próprios objetos avariados e consertá-los de maneira gratuita, com auxilio de voluntários, contado apenas, com a doação de valores espontâneos para a realização dos eventos (TONON, 2014).

Com este intuito é possível definir a problemática deste artigo, por meio da análise e compreensão dos fatores que contribuíram para o aparecimento dos grupos fixers, e de que forma eles podem influenciar na transformação de uma sociedade consumista para uma sociedade mais consciente?

Neste sentido, esta pesquisa apresenta como objetivo principal: descobrir, analisar e compreender a organização, missão, motivação e valores dos grupos fixers e a sua contribuição na redução do consumo e da rápida obsolescência dos produtos.

\section{FUNDAMENTAÇÃO TEÓRICA}

\subsection{Design e obsolescência}

O termo obsolescência originou-se do latim obsolescere, que significa tornar-se obsoleto. Este adjetivo faz referência ao processo ou estado daquilo que está em sequência de tornar-se ultrapassado ou que perdeu a sua utilidade e que, consequentemente, caiu em desuso (FERREIRA, 2010). Referindo-se também, a diminuição da vida útil e do valor de um objeto, não relacionado ao desgaste causado pelo uso, mas ao progresso técnico ou ao aparecimento de um novo produto no mercado (HOUAISS; VILLAR; FRANCO, 2001). 
Slade (2006) complementa que a obsolescência pode ser determinada por intermédio da aplicação de diversas técnicas empregadas para limitar artificialmente a durabilidade dos produtos com o único propósito de estimular o consumo contínuo. O conceito de obsolescência simboliza os elementos típicos da clássica economia de mercado, que são: a maximização da produção, a economia de escala, a fabricação de produtos de média qualidade e acelerado ciclo de depreciação e rápida troca de bens e o consequente crescimento de demanda dos usuários por novos produtos (MONT, 2008).

A partir da década de 1920 vários empresários passaram a adotar a estratégia da obsolescência como a indústria automobilística que passou a adotar as estratégias utilizadas na indústria têxtil e de moda e aplica-las em veículos automotores (PACKARD, 1965; ZACAR, 2010). Doravante, ao invés de ser necessária a busca por inovação por parte das empresas para só assim, obter o interesse do consumidor em trocar o seu produto velho por um novo, estas começaram a recorrer ao styling (ZACAR, 2010).

O styling surgiu do improvável casamento entre duas exigências contraditórias: a demanda por baixos preços, que exigia uma maior padronização na produção em larga escala dos automóveis e o apelo estético e a procura por novidades constantes e crescentes no mercado automobilístico para manter o interesse do consumidor (HESKETT, 1997).

A década de 1930 também foi marcada pela aplicação da estratégia da obsolescência, no redesign de produtos e na utilização de materiais sintéticos como, por exemplo, a baquelite (ZACAR, 2010). Uma resina termofixa de fenol-formaldeído que foi sintetizada em 1907 e em 1910 foi criada a General Bakelite Company para a exploração industrial. Foi o primeiro polímero considerado totalmente artificial, podendo ser transformado em produtos com as mais variadas formas e utilidades (CALLAPEZ, 2010).

Popularizou-se também nesta década o streamlinning principalmente nos automóveis americanos (Figura 01) (ONO, 2006). Também denominado por alguns autores de streamline, destacando-se o futuro da era da máquina, transgredindo o padrão estético da época e apresentando um design robusto, com linhas arredondadas como se fossem polidas pelo vento. Podendo ser, sobretudo, observado em veículos automotores, esta forma aerodinâmica, (ANDRIOLI; GALAFASSI, 2014). No entanto, o movimento não se resume apenas ao visual dos carros, trens e aviões, mas tornou-se uma tendência que também seria vista nas ruas e dentro dos lares da década de 30 (Figura 02) (ONO, 2006; NEUMANN, 2015).

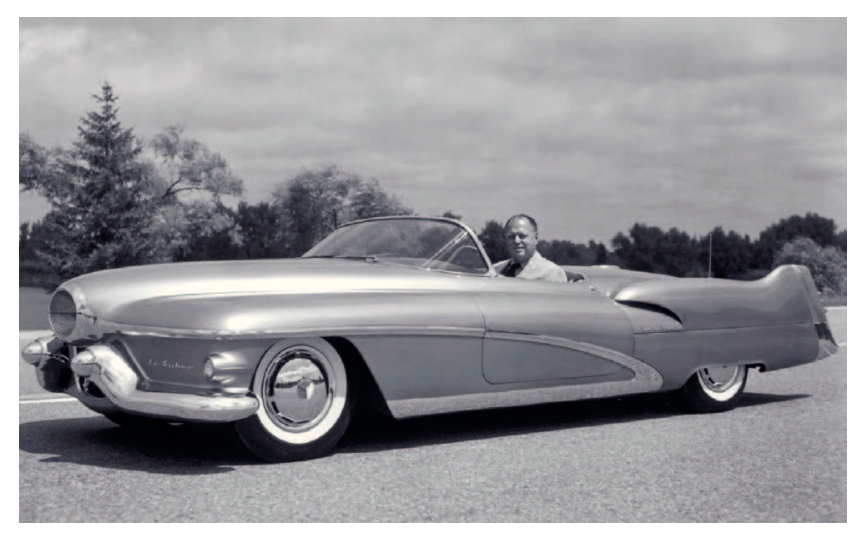

Figura 01 - Carro inspirado no movimento streamlinning Fonte: Penccil, 2015
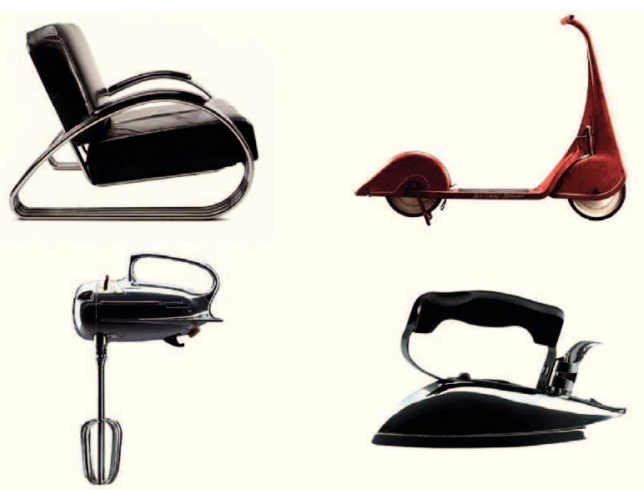

Figura 02 - Produtos inspirados no movimento streamlinning Fonte: Design Applause, 2011

Em 1940 surgiu o conceito de "Bom Design" como uma forma de reação ao styling sob a influência do Modernismo. Este movimento apresentou o desenvolvimento de produtos duráveis, funcionais e práticos, possuindo também, qualidade estética e valor coerente (ONO, 2006; ZACAR, 2010).

No ano de 1960 surgiu o "Pop Design" que rejeitava o Movimento Modernista e sua obsessão por durabilidade e funcionalidade declarando que o design deveria ser efêmero e divertido, desenvolvendo produtos com uma estética descartável (ONO, 2006; ZACAR, 2010). Segundo Zacar (2010), no final da década de 60 e início da década de 70 , começaram a despontar críticas sobre a estratégia da obsolescência aplicada nos produtos e nesta mesma época os designers começaram a se questionar sobre a sua atuação na sociedade.

Durante o ano de 1970 sobreveio o design pós-moderno que recusava a ênfase modernista na durabilidade e funcionalidade dos produtos. Segundo os pós-modernistas os objetos não deveriam ser produzidos apenas como máquinas, para cumprir uma determinada função, mas também serem carregados de um significado, pois 
as pessoas não utilizam um produto somente como ferramenta, mas, como um ícone, símbolo e/ou índice, um signo que representa seu estilo de vida e classe social (VERBEEK; KOCKELKOREN, 1998; ZACAR, 2010).

A partir de 1990 a estratégia da obsolescência volta a ser discutida devido ao surgimento de questões voltadas ao desenvolvimento sustentável (COOPER, 2004; ZACAR, 2010). Não obstante, a técnica da obsolescência é amplamente utilizada pelas empresas atualmente, considerada por muitos economistas, como essencial para o progresso tecnológico, sendo preferível a rápida obsolescência dos produtos ao invés da alta durabilidade e a lenta inovação (MONT, 2008; ZACAR, 2010).

Destarte, o design pode ser considerado uma peça fundamental na busca por alternativas mais sustentáveis e que da mesma forma também possam gerar inovação, sem recorrer auxilio constante da estratégia de obsolescência que muitas vezes pode ser considerada apenas, uma alteração superficial no produto e não uma inovação.

\subsubsection{Obsolescência planejada}

Conhecida também como obsolescência programada ou de qualidade, esta técnica consiste no encurtamento da vida útil de um produto, de maneira que os usuários sejam obrigados a comprar em um curto espaço de tempo novos artefatos para suprir a mesma finalidade, aumentando assim a lucratividade das empresas (SLADE, 2006; NEUMANN, 2015).

A fascinação que muitos homens de negócios passaram a sentir recentemente pela "obsolescência planejada" foi um dos importantes desenvolvimentos do período do pós guerra. Seu emprego como estratégia para influenciar seja a forma do produto seja a atitude mental do consumidor representa a quintessência do espirito de jogar fora (PACKARD, 1965, p. 49).

Esta redução planejada da durabilidade dos bens de consumo, feita muitas vezes intencionalmente pelos fabricantes, faz com que o produto deixe de funcionar devido a uma pequena avaria, dificultando o seu funcionamento e a substituição de peças, e tornando o conserto mais dispendioso do que a compra de um produto novo.

\subsubsection{Obsolescência perceptiva}

Esta forma de obsolescência, também denominada de obsolescência psicológica ou de desejabilidade, acontece quando um produto torna-se gasto na mente do usuário, pois uma nova versão, com aprimoramentos de estilo, faz com que ele se torna menos desejável (PACKARD, 1965;
NEUMANN, 2015). Löbach (2011) descreve esta forma de obsolescência como sendo a desvalorização prematura de um produto sobre o ponto de vista emocional. Esta estratégia é amplamente utilizada pelas empresas com a principal finalidade de aumentar as vendas.

A dificuldade no emprego dessa segunda forma da obsolescência como uma estratégia esta em convencer o público de que o estilo é um importante elemento na desejabilidade do produto. Uma vez aceita essa premissa, é possível criar a obsolescência na mente simplesmente mudando-se para outro estilo. As vezes, essa obsolescência de desejabilidade é chamada "obsolescência psicológica" (PACKARD, 1965, p. 64).

Esta desvalorização psicológica do produto implica na sensação de que o usuário tem ao perceber que seu produto se tornou ultrapassado, fazendo com que ele perca a desejabilidade embora, o produto, ainda se encontre funcionando e em perfeitas condições de uso.

\subsection{A sociedade de consumo}

O termo consumo deriva do latim consumere que se refere ao esgotamento ou a destruição de algo, também tem sua etimologia anglo-saxônica consummation que paradoxalmente refere-se a somar e adicionar (CAMPBELL; BARBOSA, 2006). A sociedade de consumo pode englobar a comercialização de signos ou apresentar características sociológicas para, além disso, como por exemplo, o consumo de massas e para as massas, apresentando altos índices de compra e descarte de objetos, a presença da moda e o sentimento permanente de insaciabilidade sendo o consumidor principal personagem (BARBOSA, 2004) deste paradoxo etimológico.

Para Bauman (2008) todos os indivíduos são considerados antes de tudo consumidores. Em uma "sociedade de consumidores todo mundo precisa ser, deve ser e tem que ser um consumidor por vocação" (BAUMAN, 2008, p. 73). Se antes o consumo era referido como a exibição pública de posição social, agora a procura acontece por meio do prazer imediato. É o comprar frenético, compulsivo, forçado, e desconectado da necessidade e do bom senso. Como um meio de alcançar a felicidade e um sentido para a vida (LIPOVETSKY, 2007). Segundo Lipovetsky (2007, p. 336):

Queremos objetos 'para viver', mais que objetos para exibir, compramos menos isto ou mais aquilo para nos pavonear, alardear uma posição social, que com vista à satisfação emocional e corporais, sensoriais e estéticas, relacionais e sanitárias, lúdicas e distintivas [...]. Das coisas, 
esperamos menos que nos classifiquem em relação aos outros e mais que nos permitam ser mais independentes e mais móveis, sentir sensações, viver experiências, melhorar nossa qualidade de vida, conservar juventude e saúde.

De acordo com Bauman (2008) e Lipovetsky (2007), o desejo pelo novo será sempre mais forte do que a satisfação de possuir o produto que se desejava. Assim que um determinado produto é adquirido gera um prazer imediato ao indivíduo para logo em seguida dar espaço a um novo desejo. Se novas formas de pensar a sociedade vierem à tona e se impuserem, a sociedade do hiperconsumo dará lugar a outro tipo de cultura, isto é, quando a felicidade for menos ligada à satisfação de possuir o maior número de objetos e a renovação sem limites dos produtos, o ciclo do consumo excessivo estará encerrado.

\subsection{Design e sustentabilidade}

A definição de desenvolvimento sustentável mais conhecida foi proposta em 1987, no documento "Nosso Futuro Comum" também conhecido como "Relatório de Brundtland" que estabelece o desenvolvimento sustentável como sendo "aquele que atende às necessidades do presente sem comprometer a possibilidade de às gerações futuras atenderem a suas próprias necessidades" (NOSSO FUTURO COMUM, 1991, p. 46).

A sustentabilidade é considerada uma questão chave da sociedade, e atualmente o seu significado não está ligado somente a questões ambientais, ainda que esta seja, a principal origem do termo. Podendo estar ligada, ao reparo de produtos e a criação de objetos que possam ser facilmente reparados e que possam recebem uma manutenção regular (MEAD, 2012).

Cabe aos designers e fabricantes, portanto, compreender cada etapa do processo de desenvolvimento de um determinado produto, assim como os aspectos ambientais sociais e econômicos relativos a ele, representando um fator decisivo na busca da sustentabilidade no setor produtivo (THACKARA, 2008). Para o usuário cabe a tarefa de repensar a opção de fácil substituição de um produto velho por um novo, que a cultura de consumo contemporânea apresenta, ao invés da sua reparação (MEAD, 2012).

Ações que buscam repensar a ação da obsolescência, devem ser privilegiadas e colocadas em prática, pois a preservação ambiental depende de diferentes fatores que compreendem desde aspectos culturais e sociais, ate a legislação e politicas públicas (MANZINI; VEZZOLI, 2011). Para Manzini e Vezzoli (2011) a melhor maneira de desenvolver novos produtos e reduzir ao máximo os efeitos negativos, é considerar em todas as fases do projeto, as possíveis implicações ambientais ligadas ao ciclo de vida do produto, como por exemplo, a pré-produção, a produção, a distribuição, o uso e o descarte.

Portanto, o designer exerce influência sobre os processos de produção, materiais aplicados, processos de distribuição e também a utilização e descarte de um determinado produto (THACKARA, 2008). Por isso, Manzini (1994) defende que os designers devem descobrir soluções para as questões ligadas a sustentabilidade tornando-se agentes ativos na modificação de uma sociedade consumista para uma sociedade mais sustentável.

Desta forma, a atuação do profissional de design na sociedade é extremamente relevante, pois ele ocupa-se tanto com questões relacionadas aos processos produtivos, quanto a questões ligadas ao consumo e a sustentabilidade de um determinado produto. Acredita-se também que a viabilizarão do conserto, a fácil substituição de peças danificadas e a reutilização da matéria prima no final da vida útil de um produto, podem ser consideradas práticas que auxiliam na criatividade, gerando novas ideias e possibilitando diferentes oportunidades para o desenvolvimento da sustentabilidade.

\subsection{0 movimento fixer e a contracultura}

O movimento fixer pode ser considerado como uma contracultura em franco desenvolvimento, reconhecida por seus participantes mais entusiastas como uma forma de ativismo (TONON, 2014). Segundo Pereira (1984) o termo "contracultura" foi cunhado pela imprensa norte-americana durante os anos 60 para caracterizar um conjunto de manifestações culturais novas que surgiram não somente nos Estados Unidos, mas em vários outros países, especialmente na Europa e, com menor intensidade e repercussão na América Latina. Um das características do fenômeno é o fato de se opor de diferentes maneiras à cultura vigente e oficializada pelas principais instituições das sociedades. Contracultura pode ser considerada uma cultura marginal, sem reconhecimento oficial. Ou seja, é uma anticultura (PEREIRA, 1984).

Para Paes (1997) a contracultura é o inconformismo com os comerciais, as imposições dos meios de comunicação de massa, a crítica à sociedade de consumo, a rejeição aos modelos anteriores e a procura por maior liberdade de expressão e ainda, a intenção de provocar a "desacomodação" e a "desalienação" do indivíduo. Em síntese a contracultura busca por um fim a ordem agradável e apresentar um universo de dimensões e proporções desconhecidas, e ao mesmo que atrai, causa um estranhamento. 
O movimento fixer consiste em grupos de pessoas que se reúnem para consertar seus produtos quebrados ou com defeito prolongando a sua vida útil e aprendendo a repará-los no caso de uma nova necessidade (TONON, 2014). Durante os encontros as pessoas podem trazer os objetos que quiserem para serem reparados, com o auxílio de voluntários e sem nenhum custo, simplesmente pelo prazer de consertar os objetos. Nestes eventos são consertados: aspiradores de pó, ferros elétricos, lâmpadas, torradeiras, peças de roupas e até mesmo consertos mais complexos (MCGRANE, 2012).

Estes grupos estimulam a prática de consertar ou a meIhorar os objetos como, por exemplo, a substituição da tela de um celular que esta quebrada, a ponta de cabo USB que esta danificada ao invés de descartá-los e substitui-los por um novo (TONON, 2014), mostrando de uma maneira produtiva, como conscientizar as pessoas de que os objetos avariados e que são descartados prematuramente, ainda possuem valor (MCGRANE, 2012).

Por meio deste movimento de consertadores os usuários descobrem que podem consertar seus produtos que antes permaneciam guardados ou inutilizados e que provavelmente seriam descartados ao invés de consertados (TONON, 2014), pois o conserto de um produto não é considerado defeito e sim uma característica necessária de todo produto e que também pode ser considerada bela e admirável (LEMOS, 2014).

Segundo os participantes mais entusiastas deste movimento "o melhor para o planeta não é reciclar o lixo, mas sim não produzi-lo" (TONON, 2014, p. 42). Mais do que prolongar a vida útil dos produtos os fixers apresentam uma forma de reduzir a dependência em relação aos serviços de assistência e pressionar as empresas para que não dificultarem o reparo dos produtos de maneira proposital. E como centro desse movimento encontra-se a discussão sobre a obsolescência planejada. $O$ fato de alguns produtos serem desenhados para não durarem ou terem o seu conserto dificultado. Muitos problemas seriam evitados se a cultura de design e consumo não estimulassem o rápido descarte de produtos (TONON, 2014).

O movimento fixer teve início na Holanda criado pela jornalista Martine Postma dando origem à fundação Repair Café Foundation por meio de um subsídio do governo holandês, apoio de fundações e pequenas doações, os quais auxiliaram no desenvolvimento do site repaircafe.org, e na compra de um ônibus auxiliar. Trinta grupos fixers iniciaram suas atividades na Holanda (Figura 01) onde se reúnem contribuindo com suas ideias e habilidades manuais durante algumas horas por mês para consertar diferentes produtos (MCGRANE, 2012).

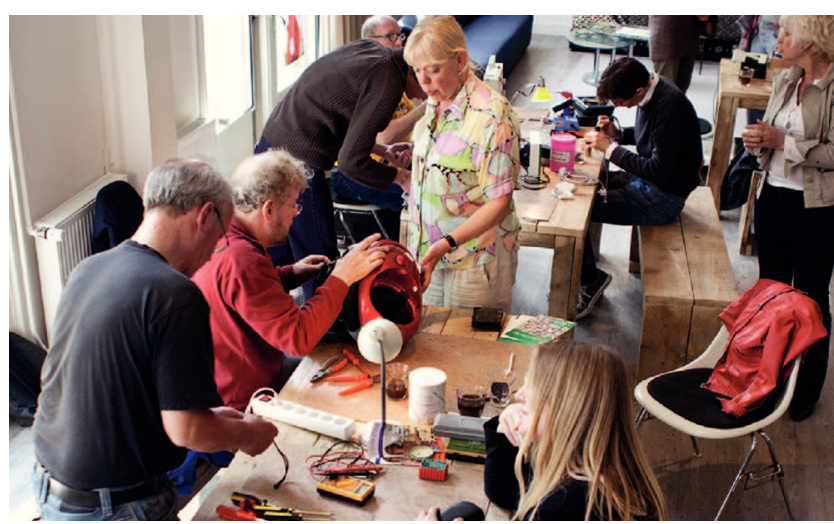

Figura 03 - Grupo fixer localizado na Holanda Fonte: McGrane, 2012

Para a criadora deste movimento era necessário não apenas escrever sobre iniciativas sustentáveis, a preservação do meio ambiente, o combate ao consumo excessivo e a rápida obsolescência dos produtos, mas promover alguma ação. E inspirada por uma exposição de design sobre os benefícios criativos, culturais e econômicos da reparação e reciclagem de produtos, decidiu auxiliar as pessoas a consertarem os seus próprios objetos de uma maneira prática evitando gastos desnecessários durante o processo (MCGRANE, 2012).

O primeiro evento do Repair Café aconteceu na cidade de Amsterdã, na Holanda, foi realizado em um teatro, em seguida, em uma sala alugada de um antigo hotel. Atualmente acontece em um centro comunitário da cidade uma vez por mês (MCGRANE, 2012). No Brasil o primeiro grupo de consertadores (Figura 02) foi estruturado na cidade de Santos, em São Paulo, chamado de Café Conserto (TONON, 2014). Funcionado desde 2012, este grupo é organizado pela Agência Nacional de Desenvolvimento Eco-Social (ANDES) com apoio do Repair Café Foundation (CAPELAS, 2014). Os encontros ocorrem mensalmente e em diferentes bairros da cidade para que o movimento seja disseminado. As atividades são organizadas em locais públicos como escolas e realizados durante as tardes de sábado (TONON, 2014).

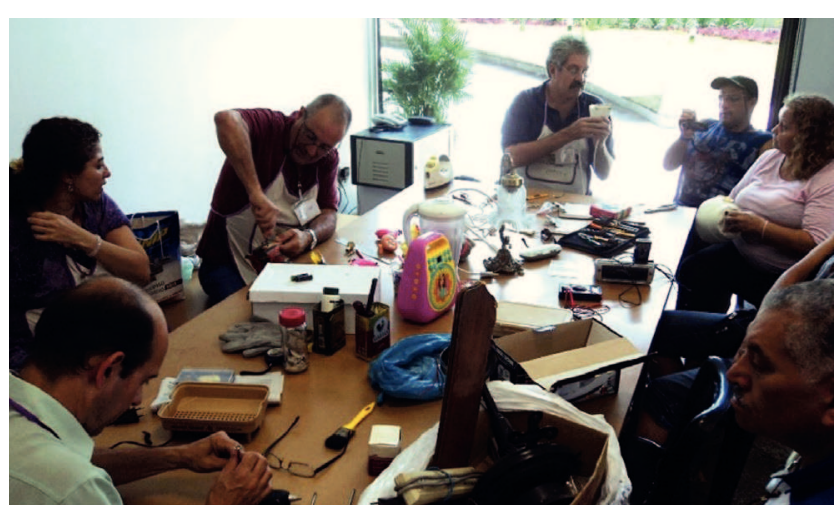

Figura 04 - Grupo fixer localizado no Brasil Fonte: Andes, 2015 
Cabe neste momento esclarecer que a Fundação Repair Café não foi criada com o intuito de ser um modelo de negócios ou como uma forma de concorrência as lojas de assistência técnica, mas apenas como uma maneira de conscientizar as pessoas que participam dos eventos sobre questões ambientais e sociais. Pressionando também as empresas a produzirem produtos que possam ser facilmente desmontados e consertados e que os materiais utilizados na fabricação possam ser reutilizados (MCGRANE, 2012).

Portanto, o movimento fixer não se trata apenas de consertar produtos que estavam avariados, mas propõe-se a inspirar seus participantes na busca por um modo de vida mais sustentável, reduzindo o consumo desnecessário de novos produtos e a produção de resíduos, e principalmente transmitir habilidades manuais, informações sobre diferentes consertos, gerando cooperação entre seus participantes, agregando mais valor emocional ao produto consertado.

\section{PROCEDIMENTOS METODOLÓGICOS}

Com o objetivo de analisar, descobrir e interpretar a organização, missão motivação e valores dos grupos fixers no combate ao consumo e a rápida obsolescência dos produtos. Este estudo foi desenvolvido sob uma abordagem de caráter exploratório qualitativo de natureza interpretativa e descritiva, utilizando-se a pesquisa bibliográfica e documental e o questionário como instrumento principal para a coleta de dados. O questionário foi formulado com perguntas abertas, nas quais o entrevistado não foi direcionado a uma única resposta.

A aplicação do questionário foi feita de forma online, sendo direcionada para o líder do grupo e aplicado em dois idiomas, português e inglês. Este estudo também utilizou como base a metodologia de Moraes (2010), abordada em seu livro "Metaprojeto: o design do design" com algumas modificações que viabilizaram um melhor aproveitamento do método para o desenvolvimento de uma pesquisa que visa conhecer o surgimento e a atuação dos grupos fixers.

De acordo com Moraes (2010), o modelo metaprojetual se estabelece por meio de uma formatação e prospecção teórica que antecede a fase de projeto, ao compor uma ou mais possibilidades projetuais por intermédio de novas propostas conceituais. Considerando seu caráter abrangente o metaprojeto experimenta todas as potencialidades do design, mas não produz soluções técncias pré-estabelecidas, apresentando-se como um complexo sistema de conhecimentos prévios que servem como guia para o processo projetual.
Para Deserti (2007) o metaprojeto é o processo capaz de proporcionar a inovação, não estando necessariamente ligado ao processo executivo do projeto, mas sim ao processo de ideação por meio da pesquisa e desenvolvimento. Já para Celaschi (2007) é a ideação e a organização do processo de pesquisa do projeto, também chamado por ele de "projeto do projeto", estando sempre voltado para a inovação.

\subsection{Coleta de dados e amostra}

A coleta de dados realizada com os grupos fixers ocorreu de maneira virtual, por intermédio da rede social Facebook e por e-mail. O questionário poderia ser respondido de forma online por meio do site Typform.com, contendo ao todo 20 perguntas. A pesquisa foi enviada para 100 grupos, localizados em diferentes países, durante os dias 11 de setembro de 2015 e 01 de outubro de 2015, obtendo o total de 15 respostas (retornos). Dentre eles, 1 grupo brasileiro e 14 grupos estrangeiros. Diante dessas considerações buscou-se conhecer os grupos fixers, sendo o resultado deste levantamento fundamental para análise apresentada a seguir, implicando no cruzamento dos dados coletados com a fundamentação teórica.

\section{APRESENTAÇÃO E ANÁLISE DOS RESULTADOS}

Na sequência estão apresentadas todas as perguntas realizadas, seguindo uma transcrição que procura contiguar e sintetizar todas as respostas obtidas dos grupos respondentes.

Pergunta 1. Nome completo do grupo fixer e localização: São os grupos questionados: Café Conserto, localizado na cidade de Santos, no Brasil; Fix It!, na cidade de Princes Hill, na Austrália; Hennepin County Fix-It Clinics, localizado na cidade de Minneapolis, nos Estados Unidos; Kingston Repair Café, na cidade de Kingston, nos Estados Unidos; NE Seattle Tool Library Fixer's Collective, em Seattle, nos Estados Unidos; Otelo - Offenes Technologielabor Gmunden, localizado na cidade de Gmunden, na Áustria; Pop Up Repair, de Nova lorque, nos Estados Unidos; Quinte Repair Café, situado na cidade de Belleville, no Canadá; Repair Café Graz, da cidade de Graz na Áustria; Repair Cafe-Hudson Valley, de Nova lorque, nos Estados Unidos; Repair Cafe Pasadena, localizado na cidade de Pasadena, nos Estados Unidos; Repair Café Toronto, de Toronto no Canadá; Restarter Firenze, estruturado na cidade de Firenze na Itália; Rhinebeck Repair Café, de Nova lorque, nos Estados Unidos e The Big Mend, localizado na cidade de Barth na Inglaterra. 
Sete grupos fixers localizam-se nos Estados Unidos, dois grupos na Áustria, dois no Canadá, um grupo na Austrália, um na Inglaterra, um na Itália e o único grupo de consertadores existente no Brasil, presente na cidade de Santos, no estado de São Paulo (Figura 01).

\begin{tabular}{|c|c|}
\hline 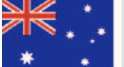 & $\begin{array}{l}\text { Austrália } \\
\text { Fix It! }\end{array}$ \\
\hline & $\begin{array}{l}\text { Áustria } \\
\text { Otelo-Offenes Technologielabor Gmunden } \\
\text { Repair Café Graz }\end{array}$ \\
\hline & $\begin{array}{l}\text { Canadá } \\
\text { Qunte Repair Café } \\
\text { Repair Cafe Toronto }\end{array}$ \\
\hline & $\begin{array}{l}\text { Brasil } \\
\text { Café Conserto }\end{array}$ \\
\hline & $\begin{array}{l}\text { Estados Unidos } \\
\text { Hannepin Country Fix-It Clinics } \\
\text { Kingston Repair Café } \\
\text { NE Seattle Tool Library Fixer's Colletive } \\
\text { Pop Up Repair } \\
\text { Repair Cafe-Hudson Valley } \\
\text { Repair Cafe Pasadena } \\
\text { Rhinebeck Repair Café }\end{array}$ \\
\hline & $\begin{array}{l}\text { Inglaterra } \\
\text { The Big Mend }\end{array}$ \\
\hline & $\begin{array}{l}\text { Itália } \\
\text { Restarter Firenze }\end{array}$ \\
\hline
\end{tabular}

Figura 05 - Grupos fixers

Fonte: Autores

\section{Pergunta 2. Quando o grupo iniciou?}

Durante o ano de 2012, surgiram cinco grupos fixers (Figura 03), incluindo o único grupo brasileiro localizado na cidade de Santos, o Café Conserto, e os demais grupos estrangeiros: Hennepin County Fix-It Clinics, dos Estados Unidos; NE Seattle Tool Library Fixer's Collective, também dos Estados Unidos; Otelo - Offenes Technologielabor Gmunden, da Áustria; The Big Mend, da Inglaterra. Em 2013, o total de grupos que iniciaram suas atividades foram cinco. São eles: Repair Café Graz, da Áustria; Repair Cafe-Hudson Valley, Repair Café Pasadena e Pop Up Repair, dos Estados Unidos; Repair Cafe Toronto, do Canadá. Já em 2014, iniciaram suas operações, também, outros cinco grupos de fixers. São eles: Restarter Firenze, da Itália; Fix It!, da Áustralia; Kingston Repair Café, dos Estados Unidos; Quinte Repair Café, do Canadá e Rhinebeck Repair Café, dos Estados Unidos.

\begin{tabular}{|c|c|}
\hline 2012 & $\begin{array}{l}\text { Café Conserto | Brasil } \\
\text { Hennepin County Fix-It Clinics | Estados Unidos } \\
\text { NE Seattle Tool Library Fixer's Collective | Estados Unidos } \\
\text { Otelo - Offenes Technologielabor Gmunden | Áustria } \\
\text { The Big Mend | Inglaterra }\end{array}$ \\
\hline 2013 & $\begin{array}{l}\text { Repair Café Graz | Canadá } \\
\text { Repair Cafe-Hudson Valley | Estados Unidos } \\
\text { Repair Cafe Pasadena | Estados Unidos } \\
\text { Repair Cafe Toronto | Canadá } \\
\text { Pop Up Repair | Estados Unidos }\end{array}$ \\
\hline 2014 & $\begin{array}{l}\text { Restarter Firenze | Itália } \\
\text { Fix It! | Austrália } \\
\text { Kingston Repair Café | Estados Unidos } \\
\text { Quinte Repair Café | Canadá } \\
\text { Rhinebeck Repair | Estados Unidos }\end{array}$ \\
\hline
\end{tabular}

Figura 06 - Início dos grupos fixers

Fonte: Autores

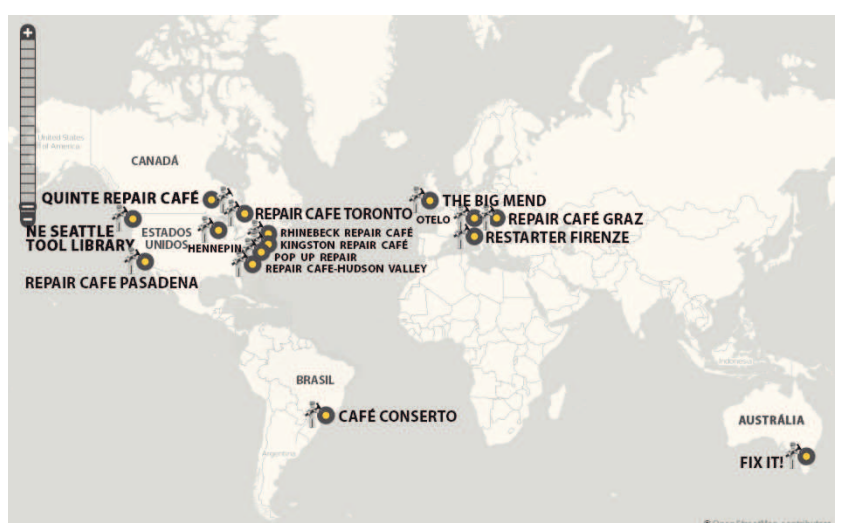

Figura 07 - Mapeamento dos grupos fixers

Fonte: Autores

Pergunta 3. O que motivou o surgimento do grupo fixer? As principais questões que motivaram o aparecimento destes grupos foi o combate à obsolescência dos produtos e serviços, principalmente a estratégia da obsolescência programada, presente em vários produtos lançados atualmente no mercado e a insatisfação constante dos usuários com a falta de reparos, muitas vezes considerada simples, para que o produto volte a funcionar, ocasionando o descarte prematuro do objeto.

Os grupos de consertadores, também, rejeitam a cultura do consumo excessivo e o desperdício exagerado de objetos, promovendo o entusiasmo de consertar produtos e a aprendizagem de novas habilidades manuais, dando vida nova à produtos que antes estavam direcionados ao lixo, proporcionando também o convívio social, a satisfação de trabalhar em equipe, a cooperação, a criatividade e a troca de conhecimento, por meio da aproximação de várias gerações presentes durante o encontro. 
Corroborando com Pereira (1984) e Paes (1997) o movimento fixer pode ser considerado uma contracultura ou cultura marginal independente do conhecimento oficial, pois se opõem a cultura vigente, neste caso o consumo excessivo e a rápida obsolescência dos produtos ao promoverem o conserto dos objetos e iniciativas sustentáveis como a preservação do meio ambiente e o convívio social.

Pergunta 4. Quantos membros fazem parte do grupo e qual a faixa etária dos membros?

Os grupos podem ser considerados pequenos em sua maioria, possuindo de dez a vinte integrantes na faixa etária dos vinte até oitenta e cinco anos. A parte das pessoas que frequentam os eventos são indivíduos maiores de idade. Contudo, o grupo Hannepin Coutry Fix-It Clinics dos Estados Unidos, possui cerca de sessenta voluntários ativos, numa faixa de vinte até setenta anos de idade.

O grupo Repair Café-Hudson Valley, também dos Estados Unidos que possui cerca de setenta e cinco voluntários de diferentes cidades na faixa de dezesseis até sessenta e cinco anos de idade. Existem poucos grupos maiores, com cerca de cento e oitenta a duzentos integrantes e abrangendo várias faixas etárias, como é o caso do The Big Mend, localizado na Inglaterra e o Repair Café Toronto, do Canadá.

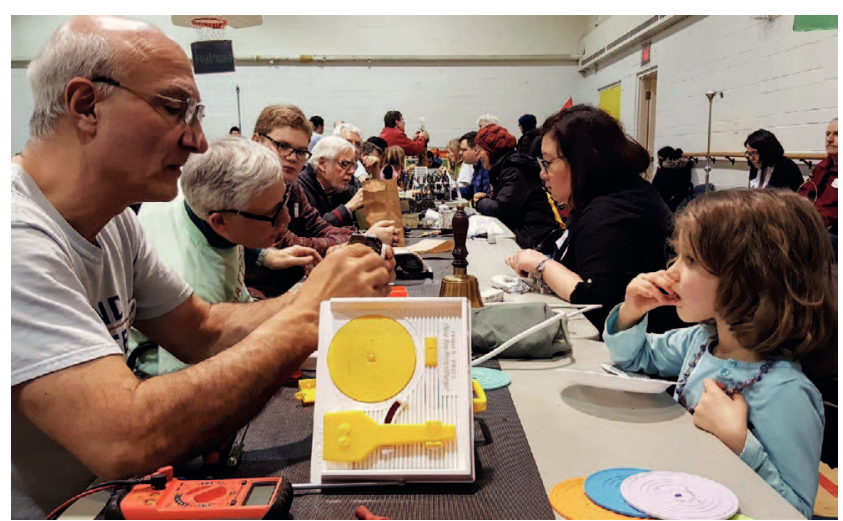

Figura 08 - Gerações participantes dos grupos fixers

Fonte: Repair Café Toronto, 2018

Pergunta 5. Quais as profissões dos membros do grupo? Fazem parte do grupo homens e mulheres de diferentes profissões, sendo elas: administradores, advogados, analistas de sistemas, aposentados, arquitetos, artistas, bibliotecários, carpinteiros, construtores, contadores, costureiras, engenheiros, enfermeiras, escritores, estudantes, funcionários públicos, jardineiros, mecânicos, poetas, podólogos, professores, programadores, psicoterapeutas, publicitários, técnicos de informática, entre outros profissionais.

Pergunta 6. Há uma classe socioeconômica predominante no grupo (classe $A, B, C, D)$ ? Se sim, qual?

A classe econômica predominante, na maioria dos grupos, corresponde à classe média. Alguns grupos não souberam responder esta pergunta, pois não dispunham informação, como é o caso do grupo The Big Mend, localizado na Inglaterra. Segundo eles, classe social e renda não são consideradas algo simples de mensurar.

Como exceção, há o grupo Repair Café Toronto, do Canadá, que afirmou ter participantes de várias classes, exceto pessoas com grande poder aquisitivo. Segundo o grupo Otelo - Ofendes Technologielabor Gmunden, localizado na Áustria, a renda dos membros pertencentes ao grupo, não tem relação com o conserto de produtos, portanto não foi definida uma classe.

Pergunta 7. O grupo possui um objetivo geral e específicos? Existe uma missão e uma visão? Se sim, quais são? Todos os grupos tiveram respostas semelhantes, fazendo referência ao conserto de produtos, e alertando sobre o consumo irrefreado, o intensificado desperdício de produtos e os impactos causados no meio ambiente com a rápida degradação dos recursos naturais devido ao estilo de vida da sociedade atual. Segundo o Quinte Repair Café "o objetivo era educar os moradores locais sobre como eles poderiam estender a vida útil de seus produtos domésticos, assim nós poderíamos reduzir o número de produtos que vão para o aterro" (tradução dos autores).

Consolidando a afirmação de Tonon (2014), que mais do que prolongar a vida a útil dos bens, os consertadores, buscam formas de reduzir a dependência dos serviços de assistência técnica e pressionar as empresas a não dificultarem o conserto de seus produtos de forma intencional.

Pergunta 8. Qual a frequência com que o grupo se encontra? A frequência de encontros dos grupos em sua maioria acontece uma ou duas vezes por mês. Existem alguns grupos como NE Seattle Tool Library Fixer's Collective, dos Estados Unidos, que promovem dois encontros durante o mês. Já o Otelo - Offenes Technogielabor Gmunden, localizado na Áustria, promove apenas quatro encontros por ano. E segundo o grupo brasileiro de consertadores, o Café conserto, o ideal é que 
os encontros sejam realizados ao menos uma vez por mês, mas para que essa regularidade aconteça são necessários recursos para gerir essa atividade.

\section{Pergunta 9. Onde são feitos os encontros?}

As reuniões dos grupos de consertadores costumam acontecer em vários locais diferentes, como por exemplo, cafeterias, câmaras municipais, centros comunitários, centros recreativos, bibliotecas, empresas privadas, escolas, estúdios, igrejas, lojas, museus, oficinas, praças e prefeituras. Apenas dois grupos possuem espaços próprios para os encontros.

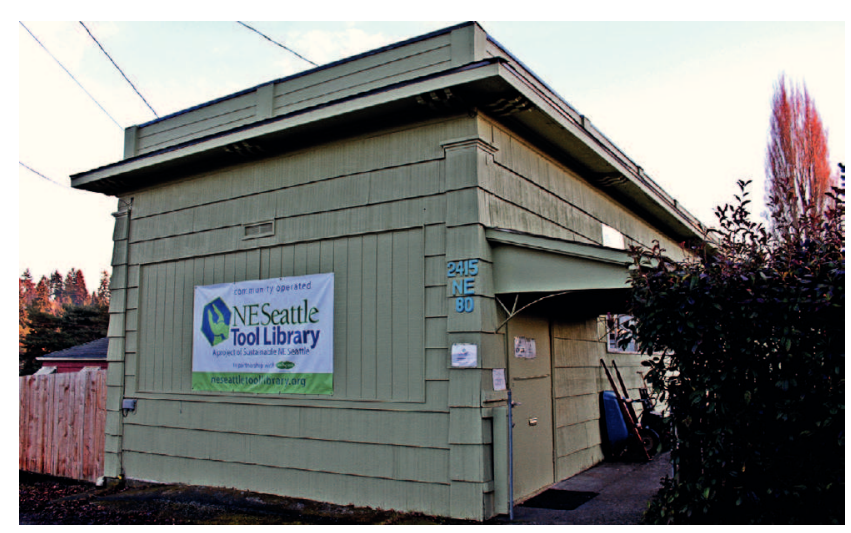

Figura 09 - Local de encontro do NE Seattle Tool Library Fixer's Collective Fonte: NE Seattle Tool Library, 2015

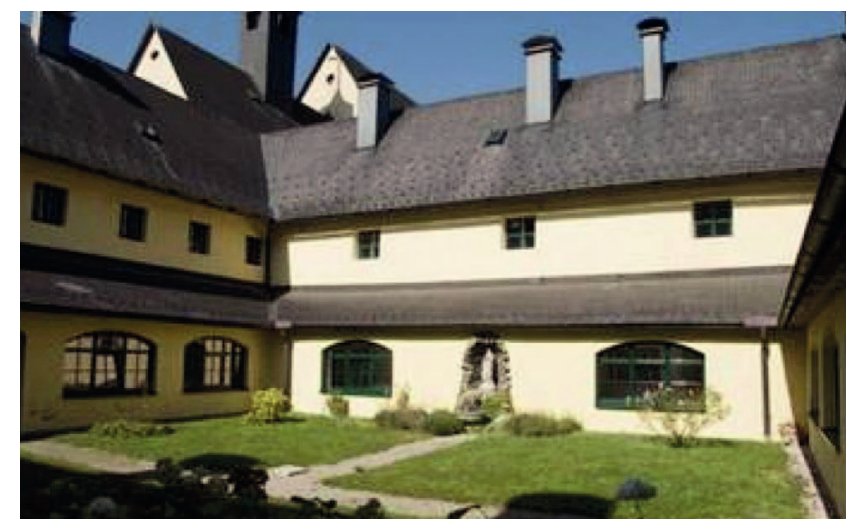

Figura 10 - Local de encontro do Otelo - Offenes Technologielabor Gmunden Fonte: Otelo, 2015

Pergunta 10. Quais os produtos mais consertados durante os encontros?

Os produtos mais consertados durante as atividades promovidas pelos grupos fixers são: aspiradores de pó, cadeiras, computadores, bolsas, brinquedos, ferramentas, lâmpadas, máquinas de café, máquinas de costura, móveis, relógios, telefones, transmissores, ventiladores, produtos de áudio e vídeo, eletrônicos e pequenos eletrodomésticos em geral. Também são consertadas peças de roupas como calças, jaquetas e peças de lã.
Pergunta 11. Em média, quantos produtos são consertados por encontro?

A quantidade de produtos consertados por encontro diverge bastante de um grupo para o outro, devido ao número de participantes e o tempo de duração de cada evento. Geralmente nos grupos pequenos são consertados de dez a quinze produtos em três horas de evento. Na reunião de grupos com maior número de participantes a média de produtos aumenta, sendo consertados até cinquenta itens em um período de quatro a cinco horas de evento.

Pergunta 12. São utilizados sites, tutoriais de consertos de produtos durante os encontros? Se sim, quais são eles? São utilizados sites, tutoriais de conserto de produtos como, por exemplo, os sites ereplacementparts.com iFixit.com, youtube.com, entre outros manuais online. Apenas três grupos fixers disseram não utilizar nenhum tipo de site ou tutorial de conserto de produtos.

Pergunta 13. Existe algum custo ou alguma exigência para o conserto de um produto?

As maiorias dos grupos fixers, não cobram nenhum valor do conserto durante os eventos eles pedem a colaboração espontânea de um valor monetário para cobrir as despesas do local onde acontecem os encontros. Caso seja necessária alguma peça de reposição ou alguma ferramenta especial para conserto esta fica por conta do proprietário do produto que está sendo consertado.

Confirmando com McGrane (2012), sobre o movimento fixer não ter sido criado com o intuito de ser um modelo de negócios ou como uma forma de concorrência as lojas de assistência técnica, mas apenas como uma forma de conscientizar as pessoas sobre questões ambientais e sociais por meio do conserto de produtos.

Pergunta 14. Existe um organograma ou um planejamento referente ao funcionamento do grupo? Se sim, como ele funciona?

Em geral os grupos fixers não possuem um organograma referente ao seu funcionamento. Pelas respostas anteriores foi possível constatar que os grupos são geralmente compostos por uma liderança que organiza os eventos de consertos de produtos. Durante estes eventos, existem os voluntários, especialistas ou não, que auxiliam os visitantes na realização do conserto de seus produtos. 
Pergunta 15. Os integrantes do grupo fazem parte de algum outro grupo, considerado também de contracultura, com atividades não diretamente relacionadas ao conserto de produtos?

A maior parte dos participantes dos grupos costuma fazer parte de algum outro grupo considerado de contracultura mas, praticamente todos citaram atividades diretamente relacionadas ao conserto de produtos. Por exemplo, os consertadores participantes do grupo localizado na Áustria, Otelo - Offenes Technologielabor Gmunden, também fazem parte de outros grupos fixers.

Pergunta 16. Os integrantes do grupo possuem hábitos em comum?

A maioria dos membros dos grupos possuem alguns hábitos em comum. O mais citado foi o fato de todos gostarem de reparar objetos e detestarem descartar seus produtos avariados e possuírem uma curiosidade natural por aprender e descobrir coisas novas, como por exemplo, aprender a consertar diferentes produtos. Conforme o grupo de consertadores, Repair CafeHudson Valley, dos Estados Unidos, eles se consideram um grupo de pessoas criativas e curiosas que gostam de fazer parte de eventos comunitários e ajudar as pessoas. Segundo eles, "O fator gratificação é muito alto. Nossos voluntários sentem que estão fazendo algo útil e eles se sentem valorizados" (tradução dos autores).

Pergunta 17. Como o grupo se posiciona (define-se) perante a produção irrefreada de produtos e serviços tornam-se rapidamente obsoletos?

Alguns grupos posicionaram-se extremamente contra a produção irrefreada de produtos criados para tornarem-se rapidamente obsoletos, afirmando o quanto esta prática de mercado é considerada insustentável, desenvolvendo alternativas contrárias às estratégias de obsolescência, sobretudo a obsolescência programada, principalmente entre participantes dos grupos de consertadores e a comunidade em que o grupo está inserido.

Outros grupos definiram-se apenas como educadores, conscientizando os participantes dos eventos sobre o valor da reparação e da reutilização de um produto, informando-os sobre como evitar produtos que apresentam uma rápida obsolescência e que possuem o reparo dificultado e, onde conseguir auxílio para consertá-los. Para o grupo Repair Café Toronto, do Canadá, o governo deveria conceber leis, que obrigassem os fabricantes a se tornarem responsáveis pelo ciclo de vida dos produtos.

Portanto, conforme afirma Manzini e Vezzoli (2011), ações que buscam repensar a obsolescência, devem ser priorizadas e colocadas em prática, pois a preservação ambiental também depende de diferentes fatores como, por exemplo, a legislação, politicas publicas, aspectos sociais e culturais.

Pergunta 18. Existem campanhas de conscientização sobre a redução do consumo, reuso e reciclagem por parte do grupo?

As campanhas de conscientização são desenvolvidas pela maioria dos grupos durante os eventos de conserto. Segundo eles a mensagem de conscientização sobre estes temas já está implícita quando um produto que seria descartado é consertado pelo seu próprio usuário, podendo ser utilizado novamente. Alguns grupos usam a sua página na rede social Facebook para divulgar temas relacionados sobre a redução do consumo, reuso, reciclagem e principalmente reparos de produtos.

O grupo The Big Mend, localizado na Inglaterra, promove um evento de conscientização durante o Dia Mundial do Meio Ambiente reunindo dados sobre a quantidade de vestuários que são descartados.

Pergunta 19. O grupo recebe apoio financeiro ou patrocínio de algum órgão, empresa, governo ou dos próprios membros?

Geralmente, os grupos não recebem apoio financeiro ou patrocínio. $\mathrm{O}$ auxílio financeiro que muitas vezes sustenta o grupo é feito pelos próprios membros. Estas doações são realizadas geralmente durante os eventos em que os visitantes e voluntários podem fazer contribuições espontâneas. Apenas alguns grupos recebem apoio financeiro do governo, igrejas locais e universidades.

De acordo com o Repair Café Pasadena "[...] mostramos para as pessoas que é possível nos reunirmos, e atingirmos um objetivo, sem nenhum dinheiro envolvido. Temos uns aos outros" (tradução dos autores).

Pergunta 20. Existem outras informações específicas sobre o grupo consideradas pertinentes para serem documentadas?

No final do questionário, os representantes dos grupos de consertadores fizeram considerações livres sobre a importância do contato social, o desenvolvimento de 
novas habilidades manuais, principalmente no conserto de produtos, a satisfação ao ver um objeto avariado funcionando novamente e o encorajamento para a criação de novos grupos de conserto.

O grupo Otelo - Offenes Technologielabor Gmunden, da Áustria, enfatizou a importância de as pessoas participarem de um grupo de conserto, levando seus objetos avariados que necessitam de reparos, aproveitando, também, para desenvolverem o contato social e aprender novas práticas no conserto de produtos. O grupo fixer Rhinebeck Repair Café, localizado nos Estados Unidos, salientou sobre a relevância das instruções e o auxílio oferecido pelos voluntários presentes durante os eventos, os quais contribuem com o seu conhecimento e suas habilidades para a realização do conserto de diferentes tipos de produtos.

Já o Hennepin County Fix-It Clinics e o Kingston Repair Café, ambos situados nos Estados Unidos, destacaram a satisfação dos voluntários e visitantes do grupo ao verem seus produtos inutilizados funcionando novamente. O Repair Cafe Pasadena, dos Estados Unidos, também costuma motivar e encorajar seus visitantes a criarem novos grupos fixers para atenderem as localidades vizinhas.

O Repair Café Graz, localizado na Áustria e o Repair Cafe Toronto, do Canadá, mencionaram sobre o auxílio prestado aos demais grupos fixers localizados em diferentes lugares para trocarem informações e novas experiências, criando uma rede sobre consertos. Já o grupo do Canadá, promove, também, o encorajamento de toda e qualquer atividade relacionada à partilha de produtos e economia circular.

Compreende-se a Economia Circular como sendo um modelo que permite repensar as práticas económicas da sociedade atual inspirada no funcionamento da natureza. É inseparável da inovação e do design de produtos e serviços. Encontra-se baseada no princípio de "fechar o ciclo de vida" dos produtos reduzindo o consumo de matérias-primas, energia e água. Promove o desenvolvimento de novas relações entre as empresas, que passam a ser consumidoras e fornecedoras de materiais reincorporados no ciclo produtivo (ELLEN MACARTHUR FOUNDATION, 2015).

Segundo o Repair Café-Hudson Valley, "há um aspecto [...] para o que fazemos expresso na letra de Leonard Cohen: "Há uma fenda em tudo, é assim que a luz entra". Perguntamos: qual item amado, mas quebrado você vai trazer? Declaramos: muitas coisas podem ser consertadas, pessoas saem muito felizes daqui. Afirmamos: Se está quebrado, traga! As palavras que as pessoas usam para descrever o Repair Café não são: "eu consertei!" ou "isso foi de graça!" elas apenas dizem: "isso foi divertido!" (tradução dos autores).

\section{CONSIDERAÇÕES FINAIS}

Repensar a sociedade atual, os padrões de consumo, a estratégia de obsolescência aplicada aos produtos e qual o papel do design nestas questões, não é mais um projeto para o futuro, estando todos estes temas relacionados às decisões do profissional de design que possui grande influência nos processos de produção de produtos, bem como os materiais utilizados, a distribuição, a utilização e o descarte. Assim o designer é capaz de desempenhar um papel importante na criação de novos cenários e sistemas mais sustentáveis. Trata-se, porém, de um desafio imensurável devido à complexidade das questões envolvidas neste processo de mudança.

Contrário a todo este processo de consumo desenfreado e a estratégia de obsolescência, surgem os grupos fixers, como uma forma de contracultura. Incentivando a prática de consertar objetos, enfatizando que o reparo de um produto não o desvaloriza, mas sim Ihe agrega uma característica diferenciada, que também pode ser considerada admirável, pois ele passa a ter uma história. Durante estes eventos também são promovidos o convívio social, o trabalho voluntário, a troca de conhecimentos, a criatividade, o desenvolvimento de habilidades manuais e a conscientização sobre um consumo mais consciente.

Portanto, entende-se que esta pesquisa abre caminho para futuras e complexas discussões envolvendo a fabricação de produtos mais duráveis, de fácil reparo, evitando o consumo excessivo e a rápida obsolescência dos produtos, sobretudo em defesa do meio ambiente e garantindo uma sociedade mais sustentável para às presentes e futuras gerações. Abrangendo, também, uma educação que possibilite aos indivíduos uma forma mais consciente de interpretar a sociedade de consumo na qual estão inseridos, tornando-se críticos, criativos, e consequentemente mais livres.

Cabe neste momento, informar sobre as limitações do estudo aqui exposto. Compreendendo que, devido ao método qualitativo utilizado nesta pesquisa "não se permite obter resultados conclusivos, isto é, tais resultados não podem ser adotados como único recurso para tomar uma decisão" (MALHOTRA, 2006, p. 154). Os resultados e as considerações finais deste estudo, não esgotam o tema abordado. Esperase que esta pesquisa contribua para o vislumbre de possíveis soluções para questões aqui tratadas, por meio da disseminação e reflexão sobre todos os temas aqui expostos. 


\section{AGRADECIMENTOS}

Aos grupos fixers que se disponibilizaram a colaborar com esta pesquisa respondendo ao questionário proposto. A participação e o apoio destes grupos foram fundamentais no desenvolvimento deste estudo.

\section{REFERÊNCIAS}

ANDES. Café Conserto. Disponível em: <http://andesbrasil.org.br/projetos/\#!mg_ld=96> Acesso em: 20 mar. 2018.

ANDRIOLI, Irineu; GALAFASSI, Ana. Styling: o design americano do século XX e seu legado para o mundo contemporâneo. P\&D Design, Gramado, 2014.

BAUMAN, Zygmunt. Modernidade líquida. Rio de Janeiro: Zahar, 2015.

Vida para consumo: a transformação das pessoas em mercadoria. Rio de Janeiro: Zahar, 2008.

BARBOSA, Lívia. Sociedade de consumo. Rio de Janeiro. Zahar, 2004.

CALLAPEZ, Maria E. Plásticos na sociedade portuguesa rural. Revista Brasileira de história e ciência, Rio de Janeiro, v. 3, n. 2, p. 200-2010, jun. dez, 2010.

CAMPBELL, Colin; BARBOSA, Lívia (org.). Cultura, consumo e identidade. Rio de Janeiro: FVG, 2006.

CAPELAS, Afonso J. Que tal um café conserto?. Planeta Sustentável, 1 ago. 2014. Disponível em: <http://planetasustentavel.abril.com.br/blog/sustentavel-napratica/ que-tal-um-cafe-conserto/> Acesso em: 1 nov. 2017.

CARDOSO, Rafael D. Uma introdução à história do design. São Paulo: Blucher, 2008.

CELASCHI, Flaviano. Dentro al progetto: appunti di merceologia contemporanea. In: CELASCHI, F.; DESERTI, A. Design e innovazione: strumenti e pratiche per la ricerca applicata. Roma: Carocci Editore, pp. 15-56, 2007.

COOPER, Tim. Inadequate life? Evidence of consumer atitudes to product obsolescence. Journal of Consumer Policy, n. 27, p. 421-449, 2004.
DESERTI, Alessandro. Intorno al progetto: concretizzare l'innovazione. In: CELASCHI, F.; DESERTI, A. Design e innovazione: strumenti e pratiche per la ricerca applicata. Roma: Carocci Editore, pp. 57-121, 2007.

DESIGN APPLAUSE. American streamlined design. 2011. Disponível em: < https://designapplause.com/ events/american-streamlined-design/12759/> Acesso em: 20 mar. 2018.

ELLEN MACARTHUR FOUNDATION. Growth Within: a circular economy vision for a competitive Europe. Cowes, Isle of Wight: Ellen MacArthur Foundation, 2015.

FEATHERSTONE, Mike. O desmanche da cultura: globalização pós-modernismo e identidade. São Paulo: Studio Nobel/SESC, 1997.

FERREIRA, Aurélio B. de H. Dicionário Aurélio da língua portuguesa. 5. ed. Curitiba: Positivo, 2010.

HESKETT, John. Desenho industrial. Rio de Janeiro: José Olympio, 1997.

HOUAISS, Antônio; VILLAR, Mauro de S.; FRANCO, Francisco $M$. de $M$. Dicionário Houaiss da língua

LEMOS, Manuel. Não jogue fora! Conserte e seja um consertador!. iMasters, 01 ago. 2014. Disponível em: < https://imasters.com.br/gerencia-de-ti/tendencias/ nao-jogue-fora-conserte-e-seja-um-consertador/>. Acesso em: 31 outubro. 2017.

LIPOVETSKY, Gilles. A felicidade paradoxal: ensaio sobre a sociedade do hiperconsumo. São Paulo: Companhia das Letras, 2007.

Gilles. 0 império do efêmero: a moda e seus destinos nas sociedades modernas. 4. reimpr. São Paulo: Companhia das Letras, 2009.

LÖBACH, Bernd. Design industrial: bases para configuração dos produtos industriais. São Paulo: Blucher, 2011.

MAGERA, Márcio. Os caminhos do lixo: da obsolescência programada à logística reversa. São Paulo: Átomo, 2013. 
MALHOTRA, Naresh K. Pesquisa em marketing: uma orientação aplicada. 4. ed. Porto Alegre: Bookman, 2006.

MANZINI, Ezio. Design: environment and social quality: "Existenzminimum "to" quality maximum. Design, London, v. 10, n.1, p. 37-43, 1994.

MANZINI, Ezio; VEZZOLI, Carlo. O desenvolvimento de produtos sustentáveis: os requisitos ambientais dos produtos industriais. 1. Ed. 3 reimpr. São Paulo: Editora da Universidade de São Paulo, 2011.

MARLET, Joaquim V. Diseño ecológico. Barcelona: Blume, 2005.

MCGRANE, Sally. Na effort to bury a throwaway culture one repair at a time. The New York Time, 8 maio 2012. Disponível em: < http://www.nytimes. com/2012/05/09/world/europe/amsterdam-tries-to-change-culture-with-repair-cafes.html?mcubz=0> Acesso em: 5 out. 2017.

MEAD, derrick. Designing for Repair: Things Can Be Fixed. 2012. Disponível em: <http://designresearch. sva.edu/research/designing-for-repair-things-can-be-fixed-2/\#fnref:1419-1> Acesso em: 15 mar. 2018.

MONT, Oksana. Innovative approaches to optizing design and use of durable consumer goods. International Journal of Product Development, v. 6, n. 3-4, 2008.

MORAES, Dijon D. Metaprojeto: o design do design. São Paulo: Blucher, 2010.

NE SEATTLE TOOL LIBRARY. About us. Disponível em: $<$ http://neseattletoollibrary.org/aboutus/>. Acesso em: 20 mar. 2018.

NEUMANN, Daniela. Fixers: contracultura em ascensão. 2015. Monografia (Graduação em Design) Centro Universitário UNIVATES, Lajeado, 24 nov. 2015. Disponível em: <http://hdl.handle.net/10737/1041>. Acesso em: 20 mar. 2018.

NOSSO FUTURO COMUM: comissão mundial sobre meio ambiente e desenvolvimento 2. ed. Rio de Janeiro: Fundação Getúlio Vargas, 1991.
ONO, Maristela, M. Design e cultura: sintonia essencial. Curitiba: Edição da Autora, 2006.

OTELO OFFENES TECHNOLOGIELABOR. Another Record at Repair Café!. Disponível em: < http:// www.otelo.or.at/standort/gmunden> Acesso em: 20 mar. 2018.

PACKARD, Vance. A estratégia do desperdício. São Paulo: Ibrasa, 1965.

PAES, Maria H. S. A década de 60: rebeldia, contestação e repressão política. 4 ed. São Paulo: Ática, 1997.

PAPANEK, Victor J. Design for the real world: human ecology and social change. Nova York: Random House, 1972.

PENCCIL. Streamlining. Disponível em: $<$ http://www. penccil.com/gallery.php? $\mathrm{p}=322652783095>$ Acesso em: 20 mar. 2018.

PEREIRA, Carlos A. M. O que é contracultura. 2 ed. São Paulo: Brasiliense, 1984.

SANTOS, Agnaldo. Níveis de maturidade do design sustentável na dimensão ambiental. In: MORAES. D. (Org.); KRUCKEN, L. (Org.). Cadernos de estudos avançados em Design. Barbacena, MG: EdUEMG, 2009.

SLADE, Giles. Made to break: technology and obsolescence in America. Washington: Harvard, 2006.

SUDJIC, Deyan. A linguagem das coisas. Rio de Janeiro: Intrínseca, 2010.

THACKARA, John. Plano B: o design e as alternativas viáveis em um mundo complexo. São Paulo: Saraiva, 2008

TONON, Rafael. O mundo tem conserto. Revista Galileu, São Paulo, n. 271, p. 40-51, set. 2014.

VERBEEK, Paul. P.; KOCKELKOREN, Petran. The things that matter. Design Issue, v. 14, n. 3, out. 1998.

ZACAR, Cláudia R. H. Design e flexibilidade: estratégias para o gerenciamento da obsolescência de telefones celulares. Dissertação de mestrado em Design, 
Programa de Pós-graduação em Design, Universidade Federal do Paraná. Curitiba, 2010.

\section{Citações diretas dos grupos fixers}

QUINTE REPAIR CAFÉ. Entrevista concedida a pesquisadora Daniela Neumann, em 6 out. 2015.

REPAIR CAFÉ-HUDSON VALLEY. Entrevista concedia a pesquisadora Daniela Neumann, em 2 out. 2015.

REPAIR CAFÉ PASADENA. Entrevista concedida a pesquisadora Daniela Neumann, em 1 out. 2015.

\section{AUTORES}

ORCID: https://orcid.org/0000-0002-0873-6245

DANIELA NEUMANN | Universidade Federal do Rio Grande do Sul | Departamento de Design e Expressão Gráfica | PGDesign | Porto Alegre, RS. Brasil | Correspondência para: Avenida Oswaldo Aranha, no99 - 60 andar - sala 607 - CEP 90035-190, Porto Alegre - RS | E-mail: danineumannd@gmail.com

ORCID: https://orcid.org/0000-0002-0873-6245

RODOLFO ROLIM DALLA COSTA, MSC. | Universidade de Caxias do Sul | Departamento de Design | Caxias do Sul, RS. Brasil | Correspondência para: Campus 8, Avenida Frederico Segala, 3099, Samuara - Caxias do Sul - RS | E-mail: rrdcosta@ucs.br

ORCID: https://orcid.org/0000-0002-8970-7015

JOCELISE JACQUES DE JACQUES, DRA. | Universidade Federal do Rio Grande do Sul | Departamento de Design e Expressão Gráfica | PGDesign | Porto Alegre, RS. Brasil | Correspondência para: Avenida Oswaldo Aranha, n॰99 - $6^{\circ}$ andar - sala 607 - CEP 90035-190, Porto Alegre - RS | E-mail: jocelise.jacques@ufrgs.br

ORCID: https://orcid.org/0000-0002-4435-6012

JULIO CARLOS DE SOUZA VAN DER LINDEN, DR. | Universidade Federal do Rio Grande do Sul | Departamento de Design e Expressão Gráfica | PGDesign | Porto Alegre, RS. Brasil | Correspondência para: Avenida Oswaldo Aranha, n॰99 - $6^{\circ}$ andar - sala 607 - CEP 90035-190, Porto Alegre - RS |E-mail: julio.linden@ufrgs.br

\section{COMO CITAR ESTE ARTIGO}

NEUMANN, Daniela; COSTA, Rodolfo Rolim Dalla;JACQUES, Jocelise Jacques de; LINDEN, Julio Carlos de Souza van der. Fixers: Contracultura em Ascensão. MIX Sustentável, [S.I.], v. 4, n. 3, p. 33-47, out-mar. 2018. ISSN 24473073. Disponível em: <http://www.nexos.ufsc.br/index.php/ mixsustentavel $>$. Acesso em: dia mês. ano. doi:https://doi. org/10.29183/2447-3073.MIX2018.v4.n3.33-47.

DATA DE ENVI0: 07/07/2018

DATA DE ACEITE: 01/08/2018 